\title{
Eco-Translatology Perspective on the English Translation of Subtitles in the Documentary Eight Hundred Years of Chu State
}

\author{
Zhang Shuyue $^{1} \&$ Wang Feng ${ }^{1}$ \\ ${ }^{1}$ School of Foreign Studies, Yangtze University, P. R. China \\ Correspondence: Wang Feng, School of Foreign Studies, Yangtze University, Hubei Province, 434023 P. R. China. \\ Tel: 86-155-7215-1282. E-mail: wangfeng@yangtzeu.edu.cn
}

Received: July 9, 2019; Accepted: July 25, 2019; Published: July 25, 2019

This research is supported by the Ministry of Education Humanities and Social Sciences 2015 Youth Fund under Grant [15YJC740078], and Hubei Provincial Institutions of Higher Education Humanities and Social Sciences Research Award under Grant [2018ZA31].

\begin{abstract}
Based on the concept of translational eco-environment, oriental ecological wisdom, and the Darwinian principle of natural selection, the concepts of eco-translatology and relevant theoretical ideas were proposed and explained by Professor Hu Gengshen from 2001 on. This interdisciplinary theory of translation studies and ecology considers translation as a translator's adaptation and selection activities, and its translation methods include the linguistic, cultural, and communication aspects. Eight Hundred Years of Chu State is a large-scale documentary about Chu culture. It systematically tells about the great history of the 800 years of Chu State, interpreting the brilliant and splendid civilization of Chu with its magnificent cultural relics, and revealing the laws worth pondering behind its ups and downs. Taking as examples the Chinese-English subtitle translations of the documentary Eight Hundred Years of Chu State, this paper aims to take the interdisciplinary theoretical perspective of eco-translatology to explore its implications for documentary translation from the linguistic, cultural, and communicative dimensions. Aiming also to improve the English translation of Chinese-made documentaries to a higher level, this paper hopes to promote the spread of Chinese traditional culture, especially Jingchu culture, and to enhance the world's understanding of China and its splendid culture.
\end{abstract}

Keywords: eco-translatology, Eight Hundred Years of Chu State, subtitle translation, documentary translation

\section{Introduction}

As Chinese culture goes out, Sino-foreign exchanges are increasing. The promotion of Chinese traditional culture is crucial for the building of China's national image. In the spring of 2014, Hubei Radio and Television Station and CCTV Documentary Channel produced the humanities documentary Eight Hundred Years of Chu State. In the historical order, the documentary takes the achievements of the Chu kings of the past generations as nodes, artistically presents the whole process of the Chu State from the rise to the demise, and creatively explains the influences of Chu culture to the Central Plains culture and later Chinese culture. (Hubei Daily, 2014) After the broadcast of the documentary, people were enthusiastic. It is important not only for us to learn our own traditional culture, but also for foreigners who do not understand Chinese traditional culture to learn about and promote Chinese traditional culture. However, in intercultural communication, the documentary can only improve its acceptance among foreign audiences by virtue of excellent subtitles, if dubbing is too expensive or impractical. However, the research on documentary subtitle translation at home and abroad mainly focuses on translation strategies, which cannot provide systematic guidance for subtitle translation. Eco-translatology proposed by Professor $\mathrm{Hu}$ Gengshen provided a new perspective for translation studies.

This paper intends to study the Chinese-English subtitle translations of the documentary Eight Hundred Years of Chu State from the perspective of eco-translatology in light of its characteristics, and explore the corresponding translation strategies to better spread Chinese traditional culture.

\section{Characteristics of Documentary Subtitle Translation}

A documentary is an important form of film and television production that will create artistic works from real life. As a film and television work, the documentary has pictures on the screen and complementary words spoken by 
the characters. (Zhang, 1998) The voices of the documentary are displayed in subtitles, supplementing the screen information to help the audience better understand the program. Subtitle translation, an important part of the introduction of foreign documentaries, recreates reality for the target audience. In the process of subtitle translation, the translator should give full play to its functions, ensure its quality, and carefully arrange the translations to match the target language with the source language. It is essential to keep the original information, reconstruct the facts, and make the target audience have the same psychological feelings of the source audience, thus achieving the purpose of cultural communication. (Lin, 2012) The documentary is both real and artistic, and the translation of the documentary subtitles is also seen as a bridge between Chinese and Western cultural communication and plays a vital role in cultural exchanges. Professor Qian Shaochang (2001) summarized the five characteristics of film and television language: conversational, comprehensive, instantaneous, popular, and non-note. Due to the characteristics of documentary subtitles, the subtitle translation of the documentary is different from the translation of general literary works and other film and television works. To our understanding, its main features are as follows:

\subsection{Time Limit}

The documentary is a kind of film and television work. Therefore, the sounds and images in the film cannot be separated from the text in subtitle translation. The translator must take into consideration the pictures and sounds of the film in translation. On the one hand, if the subtitles cannot be expressed or sufficiently expressed, the audience can get compensation from the original sound and images. On the other hand, general translation is only subject to the content of the text, but documentary subtitles are also limited by time. $(\mathrm{Li}, 2001)$ The subtitles of the documentary should be synchronized with the pictures and the commentaries. However, the display time on the screen is extremely short, the speed of commentaries is usually fast, and the changes of shots are frequent; thus, it is too late to read repeatedly to savor the taste. This time limit makes the subtitle translation of TV documentaries difficult and requires the readability of subtitles.

\subsection{Space Restrictions}

Subtitles are used as a tool to assist understanding. In order not to affect the picture, subtitles can only appear at the lower part of the screen, and the length of subtitles that can be shown on the screen is limited, so there is a certain limit in space. Depending on the size of the TV screen and the minimum size of letters that can be seen by ordinary viewers, there are usually up to two lines of subtitles on the screen, up to 35 words in a line; if there are too many words, or the subtitle font is too large, the picture effect will be affected. Therefore, the sentences translated by the subtitle translators should not be too long. It is best not to overuse explanatory words and comments. Translators need to avoid parentheses and notes, but to use techniques such as abstraction, simplification, and omission.

\subsection{Cultural Differences}

The documentary has a wide range of subjects, reflecting daily life, customs, geography, and humanities. As with other translated texts, translating documentary subtitles is not just a simple language conversion. Culture is one of the important elements to consider in translation. Different languages are spoken with different cultural backgrounds and language habits. They represent different people's behaviors, ways of thinking, and ways of language expression. Many Chinese and English words have specific expressions and their specific cultural meanings. For example, "apple" does not only refer to a fruit sometimes; "Spring and Autumn" are not always about seasons. Therefore, translators need to carefully check to well convey the original cultural factors.

\subsection{Understandability}

To be in compliance with the commentary, the subtitle translation in the TV documentary is required to be understandable, clear and concise, and natural and smooth. It is also required to keep the translated text and language style as consistent as possible with the original text. It is not advisable to be difficult and cumbersome with too many professional terms, which will directly affect the viewer's understanding, thinking, and experience. In the documentary Eight Hundred Years of Chu State, the subtitles are mainly voiceovers, with a small number of characters speaking between different scenarios, and the speed of speech is usually fast. The subtitles on each screen stay for 1 to 4 seconds, which requires the translation of subtitles to be as concise as possible and be effective in conveying information to the audience in real time.

\section{Theoretical Basis: Eco-Translatology}

Inspired by Chinese traditional ecological wisdom and the basic principles of western ecological holism, Professor $\mathrm{Hu}$ Gengshen proposed the theory of eco-translatology in 2001. Developed from the theory of translation adaptation and selection, it advocates that translation is translator's adaptation and selection activities in a translational eco-environment. Under the guidance of the Darwinian principle of natural selection, it compares the 
correlation and commonality between translation activities and the natural laws of "survival of the fittest" to explore the interrelationship, related mechanisms, basic characteristics and laws of translators in the adaptation and selection in the "translation eco-environment". It also explains the essence, process, standards, principles, and methods of translation from the perspective of adaptation and selection (Hu, 2008). Among them, "translation ecoenvironment" includes the worlds of the source text and the source and target languages (Hu, 2003: 283), in which "translation studies compared source texts and target texts to see what happened and used the results of the analysis to form prescriptive or descriptive laws" (Cronin, 2003: 9). At the same time, the theory uses the natural laws of "survival of the fittest" to propose and demonstrate the translator's central position and the translator's leading role in translation, as well as the translator's self-adaptation mechanism and the restriction of post-mortem punishment mechanism.

The theory elaborates and exemplifies its interpretative function of the translation ontology: (1) the process of translating is a production of target texts by "natural" selection via the translator's adaptation to the ecoenvironment and the translator's selection of both the degree of the adaptation and decisions about the form of the final target text; (2) translation principles are the multi-dimensional selective adaptation and adaptive selection; (3) translation methods include the linguistic, cultural, and social dimensions of translating; (4) the translation criteria are multi-dimensional, depending on reader's feedback and translator's quality, so as to get the best translation from adaptation and selection $(\mathrm{Hu}, 2003 ; 2004 ; 2006 ; 2008)$.

The methods are "three dimensional transformations" (i.e., linguistic, cultural, and communicative dimensions). (Hu, 2006) The translation on the linguistic dimension refers to the translator's adaption and selection of the language form in different aspects and different levels; that on the cultural dimension refers to the translator's interpretation of the bi-cultural connotations; that on the communicative dimension refers to the translator's adaption and selection in the pragmatic bilingual communication. In other words, the translator should pay attention to the function of the text in terms of language, culture, and communication. Translators should not only be familiar with the differences between the original language and the translated language at the linguistic level but also adopt the language style close to the target language. They should also pay attention to the cultural differences between the two languages, avoid misinterpreting the original text from the perspective of the target language and culture. At the same time, attention should be paid to adapting to the entire cultural system to which the language belongs. The adaption and selection on the communicative dimension mean that the translator pays attention to the bilingual communicative intentions in the translation process. It requires the translator to focus on communication in addition to the transformation of linguistic information and cultural connotations and to pay more attention to whether the communicative intentions in the original text are reflected in translation. In translation practice, the adaptive transformation on the three dimensions does not exist in isolation but often needs to be carried out at the same time, to ensure that the original text and the translation reach a balance and harmony of linguistic, cultural and communicative ecology.

\section{A Study of English Translation of Subtitles in Eight Hundred Years of Chu State from the Perspective of Eco-translatology}

From the perspective of eco-translatology, the above-mentioned "three-dimensional" conversion is the primary concern in translation. In a specific translation process, the translator pays attention not only to the linguistic dimension but also to the cultural dimension and communicative dimension. The three are intertwined and interconnected. The documentary Eight Hundred Years of Chu State has a refined and vivid language and a strong cultural connotation, which is of great significance to the spread of Chinese traditional culture. Eco-translatology can provide a new research perspective for documentary subtitle translation. This paper will explain the adaptive translation strategies of the subtitle translation of the documentary Eight Hundred Years of Chu State on the linguistic, cultural, and communicative dimensions of eco-translatology.

\subsection{Adaptation and Selection on the Linguistic Dimension}

The translator will make an adaptive choice in the form of language in the translation process (Hu Gengshen, 2008). On the one hand, the language features, styles, and rhetorical devices of the original text should be fully conveyed in translation. On the other hand, because of the many differences between the source language and the target language, the translation should adapt to the ecological environment of the target language, and it is not appropriate to make a hard copy or a dead translation. Translators need to be familiar with the language style, genre, rhetoric, and sentence patterns of the source text and carry out adaptive transformation to maintain a harmonious relationship between the language elements of the target language. Eight Hundred Years of Chu State is a historical documentary with a large number of historical images. With narrative techniques, each section expresses a certain fact, assisted with interviews of experts in related fields, which makes the language relatively 
more colloquial. Therefore, we need to adapt to the differences between Chinese and English colloquialism and logic when translating.

For example: 楚国已经分封, 但是“号为子男之田五十里”。那么方圆五十里, 那像现在来讲, 就不到二 十平方公里。

Translation: Chu nobles were conferred with titles and territories, but they were only conferred Viscount and a piece of land within a fifty-mile radius, which is less than 20 square kilometers.

In the example, “号为子男之田五十里” appeared in the source text. The original meaning of "号为子男之田五 十里" (Chu nobles were granted with a land covering an area of less than 20 square kilometers and the title of Viscount") is conveyed with an interpretative method. However, this example is followed by an explanation of “五十里” (fifty $l i$ ). Therefore, it is not plausible to translate the whole expression of "号为子男之田五十里". If so, the translation would be lengthy and cumbersome. Therefore, in order to adapt to the ecological environment of the target language, the Chinese expression must be well adapted for the reader's easy understanding.

\subsection{Adaptation and Selection on the Cultural Dimension}

Snell-Hornby (2001) argues that translation is a communicative act that crosses cultural barriers. Language is the carrier of culture, and different cultural characteristics will appear in translation. The adaptation on the cultural dimension requires that the translator pays attention to the transmission and interpretation of the bilingual and bicultural connotations in the translation process. The translator should examine the source language from a cultural perspective. They should fully understand the differences between the source text and the target text in terms of cultural norms, and use appropriate translation methods to maximize the reader's understanding of the source language and source culture. In the subtitle translation of the documentary, the translator should also use extralinguistic information such as the film images, sounds, and non-verbal communications between characters to help the target readers to overcome the cultural differences. Given this, the translator should not advocate the direct translation method but adopt the domestication strategy.

For example: 楚人的代表，整熊的儿子守在殿外。他眼里满是渴望，心中充满了激动。父亲为周王朝捐躯， 不知道周武王会封自己为什么。是伯？是侯？最小也会是个子爵吧。

Translation: Yu Xiong's son, the representative of Chu, was waiting outside the hall. His eyes were filled with desire; his heart swelled with excitement. His father had died for the founding of the Western Zhou Dynasty, so he was wondering what official rank he would be granted. Earl or marquis, or, at least, viscount?

In the example, “伯”, “侯” and “子爵” are three of the five ranks “公” “侯” “伯” “子” 男” in ancient Chinese feudal system. However, in Europe, the titles are usually divided into five kinds: Duke, Marquis, Earl, Viscount, and Baron, showing the hierarchy of the feudal monarchs. The European hierarchy first appeared in the Middle Ages and continues to be used in some western countries. Generally, the number of occupied lands is determined by the titles. If the translator used transliteration and explanation here, translating “伯” into "Bo, the second tier of the five ranks of nobility in ancient China", it would make the translation lengthy. In light of the space-time limitation of the subtitles, such a translation is not conducive to the understanding of the target language audience. Therefore, “伯” is domesticated as “Earl”, “侯” “Marquis”, and “子爵” "Viscount”, which not only make the translation simpler but also correspond to the cultural terms in the target culture. Even though there are differences in these ranks in the two cultures, such conversions would be better accepted by the target audience.

\subsection{Adaptation and Selection on the Communicative Dimension}

In addition to the linguistic dimension and cultural dimension, adaptation and selection also include the communicative dimension, that is, to focus on the communicative level by paying attention to whether the communicative intention of the original text is reflected in the translation $(\mathrm{Hu}, 2004)$. The role of language is not only to convey the information and cultural content but also to make people understand and respond. As is known, the content of linguistics research lies not only in semantics but also in pragmatics. This shows that pragmatic expressions are also crucial in the use of language. In translation, it is necessary to convey not only the semantic content of the original text (i.e., information on the "linguistic dimension" and "cultural dimension"), but also the pragmatic or communicative role of language. The adaptive transformation on the communicative dimension requires the translator to pay attention to the communicative intention in the source language and the target language in translating. It is essential to express the meaning of the original text adequately and to maximize the communicative ecology between the source text and the target text.

For example, 《墙盘》铭文记载, 周昭王率领着旌旗猎猎的车马, 铠甲鲜明的整齐六师, 集中全国兵力, 南下攻打楚国。 
Translation: According to the inscription on it, King Zhao of Zhou was leading a mighty army of chariots, knights and soldiers, and concentrating all forces to attack the Chu State.

In the example, “旌旗猎猎” (banners flying in the wind), “铠甲鲜明” (shining armours) and “整齐六师” (six armies in order) are all used to describe the number and power of troops led by King Zhao of Zhou, emphasizing the disparity between Chu and Zhou in military power. The use of these words allows the audience to feel the inequality between the powerful Zhou Dynasty and the weak Chu State. In translation, in order to highlight the main information in the text and achieve the communicative effect, the word "mighty army" is used to express the meaning of “整齐六师” in the source text, and words such as “chariots" "horsemen" and “soldiers” in the army are listed to further illustrate the great power of the Zhou army. Therefore, the translation realizes the communicative purpose of the original text and better realizes the adaption and selection on the communicative dimension.

\section{Conclusion}

Eco-translatology provides a new perspective for translation studies, paying more attention to the translator's ability, translation eco-environment, and the translator's adaptability to the translation eco-environment. As the documentary is an essential way of promoting communications between different countries, different nationalities, and different cultures, its subtitle translation plays an important role and deserves our attention. With an introduction to the characteristics and current situation of documentary subtitle translation, this article takes as examples several Chinese-English translations of the documentary Eight Hundred Years of Chu State, studies how the translator makes selections on the basis of adaptation, and how subtitle translation strategies on the linguistic, cultural and communicative dimensions are properly used. It provides a new perspective for the publicity of Chinese traditional culture and has a particular reference for its future promotion.

\section{References}

Cronin, M. (2003). Translation and Globalization. London: Routledge.

Hu, G. (2003). Translation as Adaption and Selection. Perspectives: Studies in Translatology, (4), 283-291. https://doi.org/10.1080/0907676X.2003.9961481

Hu, G. (2004). An Approach to Translation as Adaptation and Selection. Wuhan: Hubei Education Press.

Hu, G. (2006). Adaption in Consecutive Interpreting. Perspectives: Studies in Translatology, (1), 3-12. https://doi.org/10.1080/09076760608669013

Hu, G. (2008). Eco-translatology: A Primer. Chinese Translators Journal, (4), 11-15.

Hu, G. (2010). Eco-translatology: Backgrounds and Bases for its Development. Foreign Languages Research, (4). https://doi.org/10.13978/j.cnki.wyyj.2010.04.007

Hubei Daily. Eight Hundred Years of Chu State. March 4, 2014.

Li, Y. (2001). Strategies for Translating Subtitles. Chinese Translators Journal, (7), 38-40.

Lin, X. (2012). Analysis of Subtitle Translation in Documentaries. Journal of Xinzhou Teachers University, (6), 45-47.

Snell-Hornby, M. (2001). Translation Studies: An Integrated Approach. Shanghai: Shanghai Foreign Language Press.

Zhang, C. (1998). A Preliminary Study on Film Translation. Chinese Translators Journal, (2), 50-53.

\section{Copyrights}

Copyright for this article is retained by the author(s), with first publication rights granted to the journal.

This is an open-access article distributed under the terms and conditions of the Creative Commons Attribution license (http://creativecommons.org/licenses/by/4.0/). 